\title{
Effect of previous irradiation on the transformation of blood lymphocytes
}

\author{
R. E. MILLARD \\ From the Department of Clinical Research, Royal Marsden Hospital, London
}

SYNOPSIS The transformation of blood lymphocytes in cultures with phytohaemagglutinin was studied in five patients before and at intervals up to 18 to 19 months after therapeutic irradiation of the abdomen and pelvis (dose of $x$ rays $3,200 \mathrm{r}$ to $4,475 \mathrm{r}$ ).

In one patient, all cultures showed satisfactory lymphocyte transformation. In four patients transformation was depressed following irradiation. In three of these patients the duration of the depression was short; in one patient it was prolonged for over a year.

The poor response of the lymphocytes to phytohaemagglutinin was not associated either with leucopenia or with a high incidence of cells with chromosome abnormalities in the cultures.

When blood leucocytes are incubated with phytohaemagglutinin, a proportion of the small lymphocytes enlarge to become cells with large nuclei containing one or more nucleoli. These cells are capable of dividing. This change has been described by many workers (Nowell, 1960; MacKinney, Stohlman, and Brecher, 1962; Carstairs, 1962; Elves and Wilkinson, 1962), and is termed lymphocyte transformation. The transformed cells are known as large mononuclear cells or 'blast' cells.

During the course of an investigation into the chromosome aberrations of blood leucocytes following therapeutic irradiation, it was observed that there were only a few dividing cells in some cultures. Other workers have commented upon the poor growth of blood leucocytes from irradiated subjects (Goodlin, 1962; Lindgren and Norryd, 1962). It is not clear from their studies, however, whether the poor growth was due to failure of the cells to transform, or their failure to divide.

In this study, the percentage of transformed lymphocytes and the mitotic index in the cultures were determined before, during, and after a course of therapeutic irradiation.

\section{PATIENTS AND METHODS}

Five men whose ages ranged from 29 to 38 were studied. Each patient had had an orchidectomy for a testicular neoplasm, and was given a course of $2 \mathrm{MeV} x$ rays to the para-aortic lymph nodes and the pelvic lymph nodes on the same side as the affected testis. The total dose of $x$ rays to the para-aortic nodes ranged from $3,400 \mathrm{r}$ to

Received for publication 27 May 1965.
$4,475 \mathrm{r}$. The pelvic node dose ranged from $3,200 \mathrm{r}$ to $4,300 \mathrm{r}$.

Venous blood for leucocyte culture was taken from each patient before, during, and at intervals up to 18 to 19 months after radiotherapy. Altogether four postexposure cultures were set up from each patient. The leucocytes were cultured according to a modification of the method of Moorhead, Nowell, Mellman, Battips, and Hungerford (1960). Phytohaemagglutinin (Difco) was added to each $10 \mathrm{ml}$. culture volume in the following amounts: either Difco $P(1: 50) 0.2$ to $0.3 \mathrm{ml}$. or Difco M (1:5) 0.2 to $0.4 \mathrm{ml}$. Both types gave satisfactory lymphocyte transformation in unirradiated subjects. After a three-day incubation period, the cells were processed for chromosome studies by the standard 'Colcemid'-hypotonic citrate-fixative sequence. Slides were made from the cell suspensions by the air drying method. The preparations were stained with either $2 \%$ orcein or $1 \%$ cresyl fast violet. The percentage of 'blast' cells and the mitotic index were determined from the slides. Cells which were clearly much larger than small lymphocytes were counted as 'blast' cells: cells intermediate in size were not scored.

Each patient had a total and differential white blood cell count on the same day as the leucocytes were cultured.

RESULTS

In the control cultures before radiotherapy, the percentage of 'blasts' ranged from $19 \%$ to $39 \%$ and the mitotic index from $1.6 \%$ to $8 \%$.

The findings after exposure to $x$ rays were as follows:-

In one patient, lymphocyte transformation was satisfactory in all the cultures, the percentage of 
TABLE

\begin{tabular}{|c|c|c|c|c|c|c|}
\hline \multirow[b]{2}{*}{$\begin{array}{l}\text { Dose of X Rays } \\
\text { to Para-aortic } \\
\text { Nodes }(r)\end{array}$} & \multicolumn{5}{|c|}{ RESULTS FROM LEUCOCYTE CULTURES BEFORE AND AFTER IRRADIATION } & \multirow[b]{2}{*}{$\begin{array}{l}\text { Cells with } \\
\text { Chromosome } \\
\text { Abnormalities }(\%)\end{array}$} \\
\hline & $\begin{array}{l}\text { Time after } \\
\text { Radiotherapy (mth.) }\end{array}$ & Mitotic Index (\%) & Blasts $(\%)$ & $\begin{array}{l}\text { Total White Blood } \\
\text { Cells (per c.mm.) }\end{array}$ & $\begin{array}{l}\text { Blood Lymphocytes } \\
\text { (per c.mm.) }\end{array}$ & \\
\hline \multicolumn{7}{|l|}{ Before treatment } \\
\hline Nil. (control) & & 3 & 19 & 9,400 & 1,325 & 2 \\
\hline 1,380 & & 5 & 30 & 7,700 & 310 & 29 \\
\hline 3,360 & & Nil & Nil & 5,500 & 220 & No cells counted \\
\hline \multicolumn{7}{|l|}{ After treatment } \\
\hline & $1 \frac{1}{2}$ & 0.7 & 8 & 5,200 & 520 & 29 \\
\hline & 5 & 3 & 22 & 6,800 & 1,100 & 37 \\
\hline & 13 & 8 & 25 & 7,400 & 770 & 10 \\
\hline & 19 & 2 & 24 & 5,400 & 920 & 1 \\
\hline \multicolumn{7}{|c|}{$\begin{array}{cl}\text { Total dose of } x \text { rays } & \begin{array}{l}\text { para-aortic nodes } \\
\text { pelvic nodes }\end{array} \\
& 3,600 \mathrm{r}\end{array}$ in 36 days } \\
\hline
\end{tabular}

In three patients lymphocyte transformation was transiently depressed either immediately after or a few months after a large dose of $x$ rays. The table shows the detailed findings in one of these patients. The numbers of cells with chromosome abnormalities in the cultures are given in the last column. In this patient, the lymphocytes failed to transform after 3,360 r, and there was poor transformation one and a half months after irradiation. Thereafter, the percentage of 'blasts' was above the control value. In the second patient, depression of lymphocyte transformation was observed after 3,100 r ('blasts' $11 \%$, mitotic index $0.6 \%$ ): there was no depression of transformation in cultures set up at times ranging from two to 19 months after radiotherapy. In the third patient, depression of transformation was found on one occasion, which was four months after radiotherapy ('blasts' 7\%, mitotic index $0.5 \%$ ).

In one patient lymphocyte transformation was depressed and this lasted for more than a year after irradiation. The percentage of 'blasts' in the cultures ranged from $4 \%$ to $13 \%$. However, in the final culture 19 months after irradiation, the percentage of 'blasts' and the mitotic index were equal to the control values.

From the table it appears that, in this particular patient, the lymphocytes failed to transform when the blood lymphocyte count was lowest. However, in the other cases there was no association between a low percentage of 'blasts' in the cultures and leucopenia. For example, in the patient whose lymphocytes showed a consistently satisfactory degree of transformation, the total white cell count fell as low as 2,200 per c.mm. (lymphocytes 220 per c.mm.) during radiotherapy. Neither could a clearcut relationship be demonstrated between depression of lymphocyte transformation and a high percentage of cells with chromosome abnormalities in the cultures.

In some individuals, the transformation of lymphocytes into 'blast' cells in the presence of phytohaemagglutinin is depressed following large doses of supervoltage $x$ rays to the abdomen and pelvis. A limitation of this study is that the percentages of 'blast' cells were determined from cells which had been prepared for chromosome studies by the standard technique. Ideally, the degree of lymphocyte transformation should be measured from smears made directly from the cultures after the three-day incubation period with phytohaemagglutinin. It is possible that pre-treatment with Colcemid and hypotonic citrate may have so altered the morphology of the cells as to make it difficult to determine the number of 'blast' cells. However, all the cultures were treated in an identical manner, and it was felt that there was a sufficient difference between the controls and some of the subsequent cultures to be of significance.

There have been very few previous observations of the growth characteristics of blood leucocyte cultures from irradiated subjects. Serial observations of lymphocyte transformation before and after irradiation have not previously been made. Tough, Buckton, Baikie, and Court-Brown (1960) cultured the leucocytes of a patient who had received 250 rads of $x$ rays to the spine. The preparations from cultures set up two days and three days after exposure were of poor quality, and it was suggested that this might be an effect of irradiation. Goodlin (1962) cultured the leucocytes from 30 patients after pelvic irradiation ( $x$-ray dose up to $2,500 \mathrm{r}$ ), and he obtained satisfactory preparations from only onethird of the cultures. He concluded that the failure of growth was related to the degree of leucopenia. If the total white blood cell count was less than 2,000 per c.mm., the culture failed to grow. In the present study, depression of lymphocyte transformation seldom appeared to be associated with lowering of 
the white blood cell count. Lindgren and Norryd (1962) observed that only one out of 13 cultures from irradiated subjects gave satisfactory preparations. They commented upon the inferior quality of the chromosomes.

There is no evidence that irradiating blood in vitro inhibits the transformation of lymphocytes in culture. Bender and Gooch (1962) irradiated blood as soon as it was taken. They did not comment on the degree of lymphocyte transformation after $\mathbf{7 2}$ hours in culture, but the percentage of transformed cells was presumably high, because 100 or more cells in metaphase were scored from each culture.

In the present study, no attempt was made to determine whether the failure of some lymphocytes to transform was a direct effect of the $x$ rays on the lymphocytes (and perhaps related in some way to the chromosome aberrations), or an indirect effect due to a circulating substance in the blood. It would be of interest to try the effect of washing the cells before culture. The effect of serum from irradiated subjects on the transformation of blood lymphocytes from non-irradiated subjects could also be investigated.

If the effect of $x$ rays is a direct one on the lymphocytes themselves, it may seem at first surprising that the irradiation of a limited part of the body could affect an appreciable proportion of the blood lymphocytes. However, extensive recirculation of lymphocytes from the blood to the lymph via the lymph nodes has been shown to occur in animals (Gowans and Knight, 1964), and this may occur in man. With the repeated irradiation of lymph nodes over a period of several weeks, it is probable that large numbers of lymphocytes would be exposed to $x$ rays. Further observations are required to determine whether the altered response of the lymphocytes to phytohaemagglutinin is a specific effect of abdominal and/or pelvic irradiation, or whether it is a more general feature following the irradiation of lymphoid tissue elsewhere in the body.

It is strongly suspected that lymphocyte transformation may have an immunological basis. Recently, it has been shown that a proportion of the blood lymphocytes from sensitized subjects enlarge and divide when they are incubated with antigens such as tuberculin (Pearmain, Lycette, and Fitzgerald, 1963; Marshall and Roberts, 1963), tetanus toxoid, poliovirus vaccine, diphtheria toxoidantitoxin floccules, and smallpox vaccine (Elves, Roath, and Israels 1963). It may be that blood lymphocytes which are unresponsive to phytohaemagglutinin after irradiation would fail to transform in the presence of specific antigens. Whether the effect of irradiation on the transformation of lymphocytes in vitro is in any way associated with the depression of the immune response by $x$ rays remains unknown.

I should like to thank Professor D. W. Smithers and Mrs. E. N. K. Wallace for allowing me to study patients in their care; and Dr. H. E. M. Kay and Dr. S. D. Lawler for their advice and criticism.

\section{REFERENCES}

Bender, M. A., and Gooch, P. C. (1962). Proc. nat. Acad. Sci. (Wash.), 48, 522 .

Carstairs, K. (1962). Lancet, 1, 829.

Elves, M. W., Roath, S., and Israels, M. C. G. (1963). Ibid., 1, 806. and Wilkinson, J. F. (1962). Nature (Lond.), 194, 1257.

Goodlin, R. C. (1962). Amer. J. Roentgenol., 87, 555.

Gowans, J. L., and Knight, E. J. (1964). Proc. roy. Soc. B., 159, 257.

Lindgren, M., and Norryd, C. (1962). Hereditas (Lund), 48, 688.

MacKinney, A. A. Jr., Stohlman, F. Jr., and Brecher, G. (1962). Blood, 19, 249.

Marshall, W. H., and Roberts, K. B. (1963). Lancet, 1, 773.

Moorhead, P. S., Nowell, P. C., Mellman, W. J., Battips, D. M., and Hungerford, D. A. (1960). Exp. Cell Res., 20, 613.

Nowell, P. C. (1960). Cancer Res., 20, 462.

Pearmain, G., Lycette, R. R., and Fitzgerald, P. H. (1963). Lancet, 1, 637.

Tough, I. M., Buckton, K. E., Baikie, A. G., and Court-Brown, W. M. (1960). Ibid., 2, 849. 